\title{
Effects of Si and Sn Contents and Heat-Treatment Temperature on the Corrosion Behavior of AISI 439 Ferrite Stainless Steel
}

\author{
Chan Yang Kim, Do hyung Kim and Won sub Chung* \\ Department of Materials Science and Engineering, Pusan National University, Kumjeong-ku 46241, Republic of Korea
}

\begin{abstract}
This study was conducted to evaluate the corrosion resistance and optimize the heat-treatment process of AISI 439 ferrite stainless steel silicon and tin alloys with reduced chromium. The microstructure of the specimens and deposition under each condition were analyzed. The production of oxide films was compared based on the thickness of the film and the change in the contents of each element. In addition, electrochemical analyses of each heat-treatment condition was used to quantitatively compare corrosion resistance and passive film stability based on the relative chromium, silicon, and tin contents. It was found that the addition of silicon and tin compensated for the decrease in corrosion resistance induced by the chromium reduction. The addition of the two elements inhibited iron $(\mathrm{Fe})$ oxide production in the surface oxide film, thereby improving the corrosion resistance of the material and improving the stability of the passive film. Moreover, the $\mathrm{SiO}_{2}$ and $\mathrm{SnO}_{2}$ layers inhibited the production of $\mathrm{Fe}$ oxide and contributed to the stability of the film along with $\mathrm{Cr}_{2} \mathrm{O}_{3}$, the main component of the passive film. However, when the heat treatment temperature increased above a specific temperature, the oxide inhibitory effect of the two elements was relatively offset. Nevertheless, further research to optimize the content of the three elements will help develop materials with superior mechanical properties and corrosion resistance.
\end{abstract}

(Received June 26, 2021; Accepted October 18, 2021)

Keywords: ferrite stainless steel, corrosion resistance, oxide layers, passive film, pitting corrosion

\section{Introduction}

Stainless steel is a type of steel with excellent corrosion resistance compared to ordinary steel materials, due to a passive film. The passive film is an ultra-thin film formed during the initial stainless steel oxidation process. This film plays an important role in the corrosion resistance of stainless steel because it prevents the exposure of the base metal to the external environment, thereby preventing oxidation of the surface. A wide variety of stainless steel species are available, depending on the intended purpose and field of use. These materials are applied extensively, in petrochemical industries, power plants, plumbing, facilities, home appliances, and household goods [1,2]. Compared to austenite stainless steel, ferrite stainless steel contains only a small amount of expensive nickel (Ni), making it relatively inexpensive. In

- 김찬양: 석사과정, 김도형: 박사과정, 정원섭: 교수

*Corresponding Author: Won Sub Chung

[Tel: +82-51-510-2386, E-mail: wschung1@pusan.ac.kr]

Copyright (c) The Korean Institute of Metals and Materials addition, this steel species has a good surface gloss, formability, and oxidation resistance. Hence, it can be used for various applications, including heat-resistant appliances, enclosures, home appliances, and electronic components. Moreover, ferrite stainless steel is economical and has excellent corrosion resistance, in line with the demand for inexpensive and efficient steel materials. Accordingly, many studies have been conducted on ferrite stainless steel, which has been recommended as an alternative to steel materials in various fields [3].

The corrosion resistance of most stainless steel is generally superior to other steel species. However, stainless steel is highly susceptible to pitting corrosion due to destruction of the passive film [4]. Pitting corrosion results when anodic dissolution occurs in a limited area of the material surface covered with the passive film. In particular, pitting corrosion can occur when the external environment destroys the passive film locally, and the melting rate of the film is faster than the recovery rate. Pitting corrosion arises with specific reactive ionic atmospheres and electrochemical potentials, 
including chlorine ions $\left(\mathrm{Cl}^{-}\right)$, and ultimately shortens the life span of the stainless steel [5]. Although several studies have been conducted on the reduction of the lifespan of stainless steel by pitting corrosion, not many have reported on the corrosion mechanisms and their causes. Therefore, further research is necessary to improve the corrosion resistance of stainless steel and its resistance to pitting corrosion, which is a globally important problem.

Stainless steel undergoes several heat-treatment processes during its manufacture. The secondary annealing process, following roll pressing, is performed several times in a hightemperature atmosphere to effectively remove hydrogen embrittlement inside the material [6]. However, this process results in rapid iron oxidation on the surface. Although the oxide produced on the surface is typically eliminated through an acid pickling process, it is complicated and challenging to eliminate the iron oxidation, and is thereby inefficient for production. Furthermore, the generation of precipitates, including chromium $(\mathrm{Cr})$ carbide and titanium (Ti) nitride, can induce galvanic effects in the material, which is fatal to the corrosion resistance and the lifespan of the material $[1,7]$. Accordingly, there are ongoing efforts to study and develop steel species to minimize the generation of iron $(\mathrm{Fe})$ oxide on the Fe surface, and simultaneously improve the corrosion resistance of the materials.

AISI 439 ferrite stainless steel typically contains 17-19 wt.\% Cr. Chromium is one of the main constituent elements of stainless steel, essential for improving corrosion resistance. During the initial oxidation process of stainless steel, the $\mathrm{Cr}_{2} \mathrm{O}_{3}$ passive film plays a key role in preventing corrosion. Several studies have been conducted on how $\mathrm{Cr}$ content affects various properties of stainless steel. Generally, the corrosion resistance increases as the $\mathrm{Cr}$ content of stainless steel increases. Specifically, studies have reported that every $1 \mathrm{wt} . \%$ increase in $\mathrm{Cr}$ content increases the value of the pitting potential, a major corrosion resistance indicator of stainless steel, by approximately $100 \mathrm{mV}[8,9]$. However, excessive $\mathrm{Cr}$ content degrades the mechanical properties of the stainless steel, such as formability, which limits the use of stainless steel in certain fields. With these considerations, the goal of the present study is to reduce $\mathrm{Cr}$ content to preserve various mechanical properties while supplementing corrosion resistance by adding other corrosion resistance-enhancing elements. In this study, the decrease in corrosion resistance resulting from the $\mathrm{Cr}$ reduction was offset by adding silicon (Si) and tin (Sn). Si acts as a reducing agent and ferrite stabilizer in the manufacturing process. Si is also reported to inhibit the production of oxides on the iron surface $[10,11]$. Moreover, $\mathrm{SiO}_{2}$ layers produced on iron surfaces enhance the stability of the passive film by inhibiting the iron oxidation of the base metal with a passive film, thereby improving the corrosion resistance of the material. In addition, an appropriate amount of Si improves the formability of stainless steel, thus improving its mechanical properties.

Adding small amounts of $\mathrm{Sn}$ to stainless steel can also improve its corrosion resistance and passive film stability. Similar to $\mathrm{Si}$, Sn reacts with oxygen on the surface to produce $\mathrm{SnO}_{2}$ layers, which has been reported to improve the stability of the passive film [5,12]. Moreover, the electromotive force (EMF) potential of $\mathrm{Sn}$ is $-0.136 \mathrm{~V}$, higher than iron $(-0.440 \mathrm{~V})$. Elements with higher EMF values will exhibit higher electrochemical stability. However, when the passive film of the stainless steel is destroyed, the galvanic effect of the potential difference between the $\mathrm{Sn}$ and $\mathrm{Fe}$ in the base metal accelerates the corrosion of the base metal $[4,5,13]$. Therefore, studies have reported that the addition of $\mathrm{Sn}$ in the range of 0.05 to 0.1 wt.\% is optimal for effectively improving the corrosion resistance of stainless steel [12]. Based on the above studies, the present work evaluated corrosion resistance and optimized the heat-treatment process for $\mathrm{Si}$ and $\mathrm{Sn}$ alloys that replaced the $\mathrm{Cr}$ composition of AISI 439 ferrite stainless steel.

\section{Experimental Methods}

The stainless steel samples were acquired from POSCO Co., Ltd. (South Korea). The samples were produced by roll pressing a thin sheet with a $1 \mathrm{~mm}$ thickness. The composition of AISI 439 ferrite stainless steel samples are illustrated in Table 1, with (\#A) containing 17 wt.\% $\mathrm{Cr}$ and stainless alloys

Table 1. Components of ferritic stainless steel \#A and \#B

\begin{tabular}{ccccccc}
\hline Specimen & $\mathbf{C r}$ & $\mathbf{S i}$ & $\mathbf{S n}$ & $\mathbf{T i}$ & $\mathbf{M n}$ & $\mathbf{F e}$ \\
\hline$\# \mathbf{A}$ & 17.6 & 0.15 & - & 0.35 & 0.1 & bal \\
$\# \mathbf{B}$ & 15.2 & 0.98 & 0.057 & 0.35 & 0.1 & bal \\
\hline
\end{tabular}


(\#B) containing 15 wt.\% Cr, Si, and $\mathrm{Sn}$. Each sample was prepared with dimensions of $20 \mathrm{~mm} \times 20 \mathrm{~mm} \times 1 \mathrm{~mm}$. In addition, to analyze the surface conditions before and after the heat treatment, grinding and polishing were performed from \#600 grit to \#2000 grit using a silicon carbide (SiC) paper, and micro-grinding was performed using a $1 \mu \mathrm{m}$ diamond suspension.

Subsequently, heat treatment was conducted for a short time after the roll pressing process to remove the hydrogen brittleness generated during the production of stainless steel during the manufacturing process at POSCO. Each heat treatment was performed for one minute in a hightemperature atmosphere at 900,950 , and $1000{ }^{\circ} \mathrm{C}$, followed by air-cooling. The obtained specimens was oxidized and etched in Viella's Reagent (ethanol $+10 \mathrm{~mL} / \mathrm{L} \mathrm{HCl}+10 \mathrm{~g} / \mathrm{L}$ picric acid) to analyze surface morphology and microstructure using an optical microscope (OM, Nikon, ECLIPSE LV150N, Japan). Additionally, a field-emission scanning electron microscope (FE-SEM, Hitachi S4800, Japan) and energydispersive X-ray spectrometer (EDS, ELECT PLUS, AMETEK, USA) were employed to obtain highmagnification images and component changes for each condition. Depth profiles (NEXA Thermophosphorous) were analyzed by X-ray photoelectron spectrophotometer (XPS) to quantitatively assess the component changes based on the depth direction of the specimen cross section. The analysis was conducted for $2500 \mathrm{~s}$ at a sputtering energy of $3 \mathrm{kV}$, sputter rate of $0.49 \mathrm{~nm} / \mathrm{s}$, and sputter size of $2 \mathrm{~mm} \times 2 \mathrm{~mm}$. An electrochemical analysis of each specimen was performed using a potentiostat (VersaSTAT 4, AMETEK, USA) to conduct a potentiodynamic polarization test, and an electrochemical impedance spectrometer (EIS, VersaSTAT 4, AMETEK, USA). A saturated calomel electrode (SCE) was used as the reference electrode. The relative electrode (CE) used a platinum mesh of $2 \mathrm{~cm} \times 2 \mathrm{~cm}$. Additionally, the gap between the working electrode (WE) and $\mathrm{CE}$ was set to $12 \mathrm{~cm}$. The test was conducted at a temperature of $25^{\circ} \mathrm{C}$ under the conditions of $\mathrm{NaCl}$ and $\mathrm{H}_{2} \mathrm{SO}_{4}$ mixed solution $\left(0.5 \mathrm{M} \mathrm{NaCl}+0.5 \mathrm{M} \mathrm{H}_{2} \mathrm{SO}_{4}\right)$ according to ASTM G 5-14. The potentiodynamic polarization test was conducted at a scan rate of $0.167 \mathrm{mV} / \mathrm{s}$ under conditions of $-0.2 \mathrm{~V}$ (vs OC) to $1.0 \mathrm{~V}$ (vs SCE) to quantitatively evaluate the corrosion resistance and electrochemical properties of the specimen.
EIS was conducted to measure the solution resistance $\left(\mathrm{R}_{\mathrm{s}}\right)$ and polarization resistance $\left(\mathrm{R}_{\mathrm{p}}\right)$, depending on the conditions of the specimen, and proceeded in the range of $1 \mathrm{~Hz}$ to $100 \mathrm{kHz}$.

\section{Results and Discussions}

\subsection{Microstructure (Optical microscope)}

Based on the heat-treatment conditions, the surface microstructures of specimens \#A and \#B were analyzed using an optical microscope, as shown in Figure 1. Similar precipitates, including $\mathrm{Cr}$ carbide and Ti nitride, were formed under heat-treatment conditions in both \#A and \#B. These deposits were randomly created inside the grain boundaries and grains. However, no significant changes were observed in the deposits produced at varying heat-treatment temperatures, due to the short heat-treatment time. Conversely, it was confirmed that the grain size of each specimen slightly increased with increasing heat-treatment temperature. In general, the grain growth occurred during the annealing process, due to an increase in the heat-treatment temperature of the stainless steel, thereby increasing the grain size. In

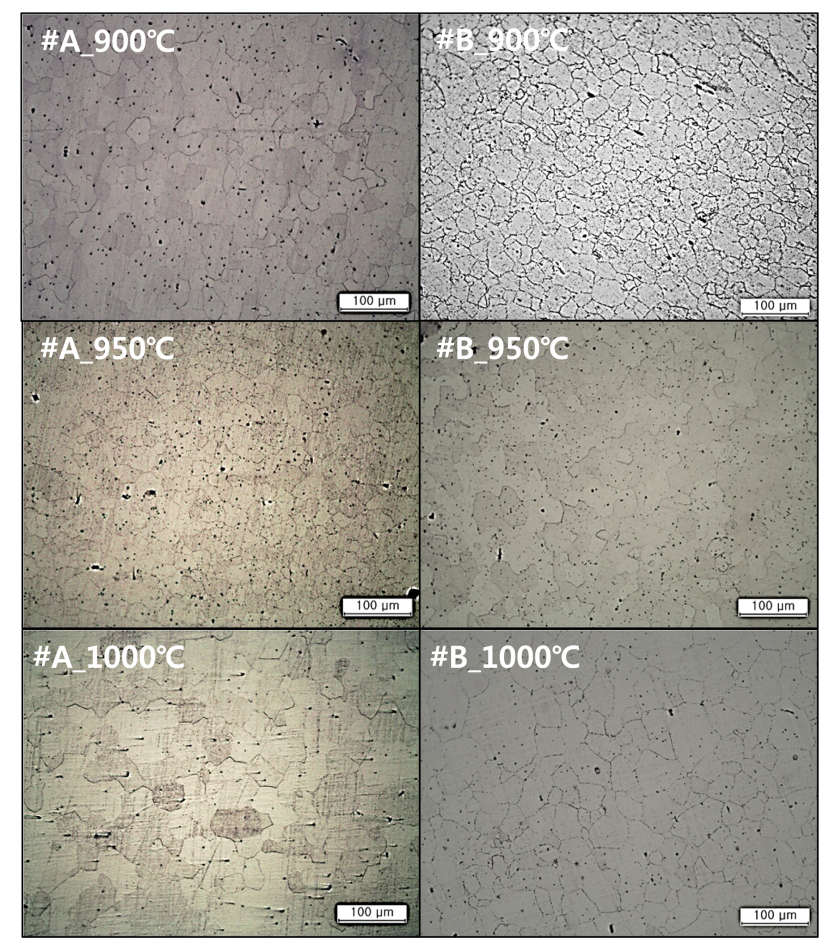

Fig. 1. Optical microscope image of surface microstructure according to heat treatment conditions. 


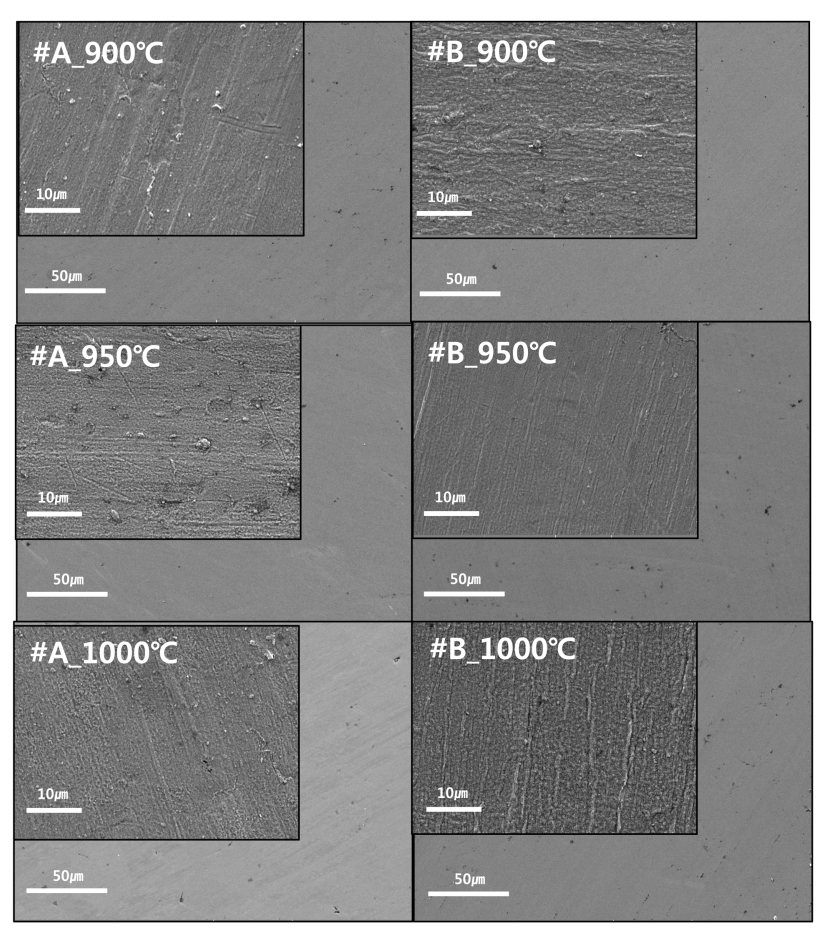

Fig. 2. SEM images before and after corrosion of surfaces by heat treatment conditions of \#A and \#B specimen.

addition, studies have reported that the corrosion resistance of stainless steel is inversely proportional to the grain size. Thus, the contact area between the base metal and the corrosion environment increased with the grain size, allowing easy exposure to the corrosion environment $[14,15]$.

\subsection{Surface analysis (SEM and EDS)}

The surface morphology of specimens under each condition was analyzed using SEM and EDS to compare and analyze the surface changes before and after corrosion, as shown in Figure 2. No significant changes were observed before and after corrosion from the SEM results. However, the formation of oxide films was common under all conditions, allowing the identification of non-uniform surfaces from the images. The results of the before- and aftercorrosion specimen surface composition ratio measured by the EDS spectrum of the surface are shown in Table 2.

An increase in $\mathrm{O}$ content from $1 \mathrm{wt} . \%$ to approximately 30 wt.\% was common for all specimens after corrosion. This is a common phenomenon, indicating that corrosion creates an oxide film on the surface. In addition, the contents of $\mathrm{Cr}$ and $\mathrm{Fe}$ were relatively reduced, indicating the production of $\mathrm{Fe}$
Table 2. Results of EDS analysis of components before and after corrosion of surfaces by heat treatment conditions of \#A and \#B specimen

\begin{tabular}{|c|c|c|c|c|c|c|c|}
\hline \multicolumn{2}{|c|}{ wt.\% } & $\mathrm{O}$ & $\mathrm{Cr}$ & $\mathrm{Fe}$ & $\mathrm{Si}$ & $\mathrm{Sn}$ & $\mathrm{Ti}$ \\
\hline \multirow{2}{*}{ \#A Bal } & Before & 0.9 & 32.9 & 56.1 & 1.3 & - & 1.9 \\
\hline & After & 34.1 & 12.8 & 38.3 & 2.5 & - & 13.3 \\
\hline \multirow{2}{*}{$\# \mathrm{~A} 900{ }^{\circ} \mathrm{C}$} & Before & 0.7 & 34.8 & 54.9 & 1.3 & 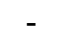 & 1.9 \\
\hline & After & 32.9 & 12.7 & 38.6 & 2.7 & - & 13.0 \\
\hline \multirow{2}{*}{$\#$ A $9500^{\circ} \mathrm{C}$} & Before & 1.0 & 33.5 & 55.7 & 1.4 & - & 1.8 \\
\hline & After & 34.4 & 15.1 & 38.9 & 3 & - & 8.6 \\
\hline \multirow{2}{*}{$\# \mathrm{~A} 1000^{\circ} \mathrm{C}$} & Before & 0.9 & 33.0 & 55.9 & 1.3 & - & 2 \\
\hline & After & 33.2 & 13.6 & 38.7 & 3.2 & - & 11.4 \\
\hline \multirow{2}{*}{ \#B Bal } & Before & 1.2 & 31.3 & 59.5 & 2.8 & 1.1 & 1.7 \\
\hline & After & 30.4 & 13.0 & 38.8 & 3.9 & 3.2 & 10.7 \\
\hline \multirow{2}{*}{ \#B $900{ }^{\circ} \mathrm{C}$} & Before & 1.0 & 29.3 & 57.4 & 2.6 & 1.0 & 1.5 \\
\hline & After & 29.6 & 11.1 & 40.3 & 4.0 & 3.7 & 11.3 \\
\hline \multirow{2}{*}{ \#B $950^{\circ} \mathrm{C}$} & Before & 0.7 & 29.4 & 57.9 & 2.8 & 1.4 & 1.5 \\
\hline & After & 28.0 & 11.0 & 41.6 & 4.3 & 4.1 & 11.0 \\
\hline \multirow{2}{*}{ \#B $1000^{\circ} \mathrm{C}$} & Before & 0.7 & 30.6 & 56.7 & 2.4 & 1.5 & 1.8 \\
\hline & After & 29.3 & 11.8 & 40.4 & 3.9 & 3.4 & 11.3 \\
\hline
\end{tabular}

oxide and $\mathrm{Cr}$ oxide in the oxide films.

Furthermore, in the case of Si present in specimens \#A and \#B, the Si content on the surface increased after corrosion, indicating that the oxide film consisted of $\mathrm{Si}$ oxide. Studies have reported that adding Si to stainless steel resulted in the formation of $\mathrm{SiO}_{2}$ layers, which increased the stability of the passive film. These layers inhibited the oxidation of Fe by contributing to the stability of the passive film [16,17]. The amount of $\mathrm{Si}$ in specimen $\mathrm{BB}$ was approximately twice that in specimen \#A, which was attributed to the difference in $\mathrm{Si}$ content. For specimen \#B containing Sn, the Sn content increased by approximately $2 \mathrm{wt} \% \%$ after corrosion. This indicated the formation of $\mathrm{SnO}_{2}$ layers on the surface oxide film. The following chemical reaction can account for the formation of $\mathrm{Sn}$ oxide layers on the surface: $[2,12,18]$

$$
\begin{aligned}
& \mathrm{Sn}+4 \mathrm{H}_{2} \mathrm{O} \rightarrow \mathrm{Sn}(\mathrm{OH})_{4}+4 \mathrm{e}^{-}+4 \mathrm{H}^{+} \\
& \mathrm{Sn}+2 \mathrm{H}_{2} \mathrm{O} \rightarrow \mathrm{Sn}(\mathrm{OH})_{2}+2 \mathrm{e}^{-}+2 \mathrm{H}^{+} \\
& \mathrm{Sn}(\mathrm{OH})_{2}+2 \mathrm{H}_{2} \mathrm{O} \rightarrow \mathrm{Sn}(\mathrm{OH})_{4}+2 \mathrm{e}^{-}+2 \mathrm{H}^{+} \\
& \mathrm{Sn}(\mathrm{OH})_{4} \rightarrow \mathrm{SnO}_{2}+2 \mathrm{H}_{2} \mathrm{O}
\end{aligned}
$$

It has been reported that the $\mathrm{Si}$ and $\mathrm{Sn}$ oxide films formed on stainless steel surfaces improved the stability of passive films by inhibiting the Fe oxidation of the base metal. Thus, 


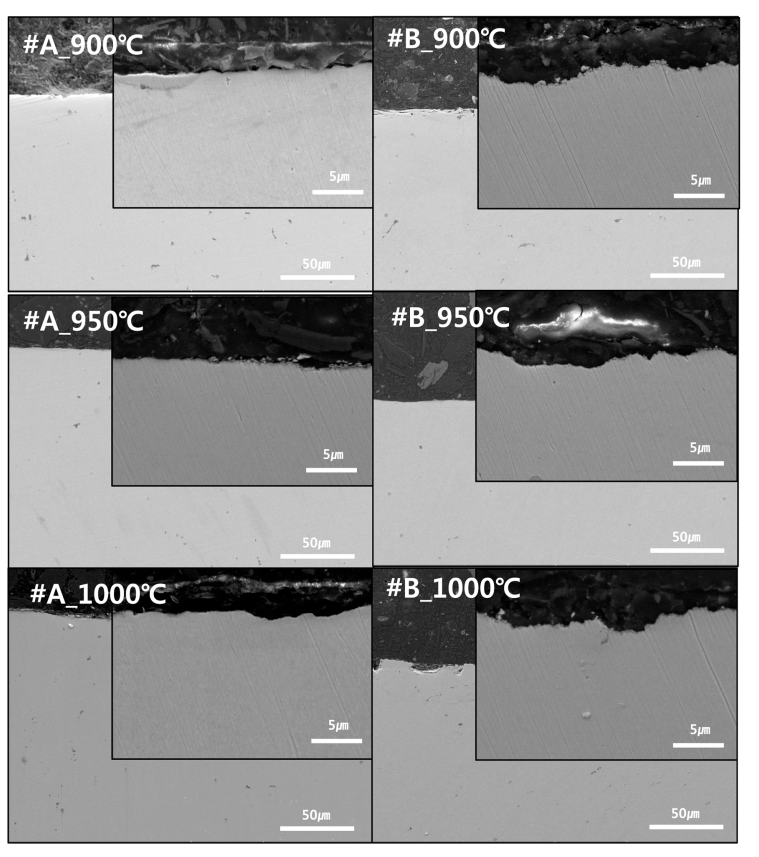

Fig. 3. Scanning electron microscope (SEM) analysis results for cross sections of $\mathrm{AA}$ and $\mathrm{BB}$ specimens under heat-treatment conditions. the decreasing Fe oxidation ratio on the surface lead to the formation of $\mathrm{Si}$ and $\mathrm{Sn}$ oxide films, thereby contributing to enhancement of the passive film stability.

\subsection{Cross-sectional analysis (Depth profiles)}

SEM images of the cross-section of each specimen based on the heat treatment conditions are shown in Figure 3. No significant differences in the $\mathrm{Cr}, \mathrm{Si}$, and $\mathrm{Sn}$ contents were observed on the surfaces of the base metal. Thus, to quantitatively clarify the differences based on the conditions, depth profiles using XPS analysis were obtained, as shown in Figure 4. These profiles determined the changes in the content of each element based on the depth direction of the specimen. Etch level indicated the length, measured in the direction of depth from the surface.

In addition, the XPS analysis showed that the film thickness of the material was approximately $1 \mu \mathrm{m}$ [19]. The oxide film thickness for each condition was relatively comparable through the intersection of $\mathrm{Fe}$ and $\mathrm{O}$. For specimen
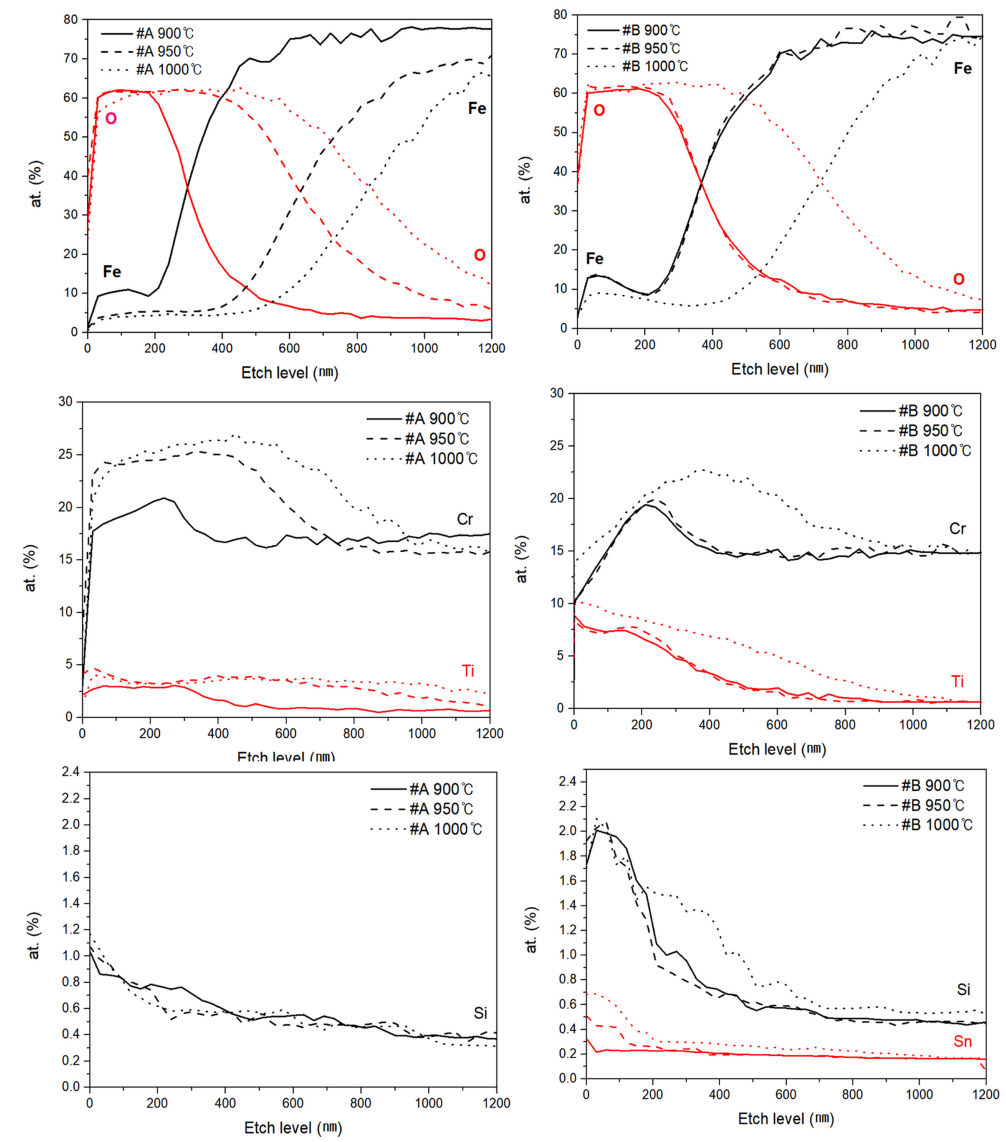

Fig. 4. Results of Depth profiles for each cross section by heat treatment conditions for \#A and \#B specimens. 


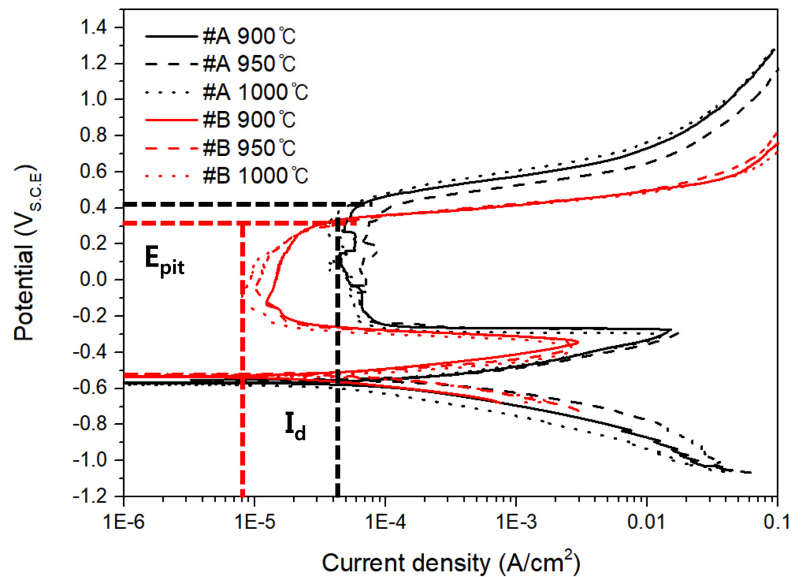

Fig. 5. Results of potentiodynamic polarization test by heat treatment conditions of \#A and \#B specimens.

\#A, the increasing temperature increased the Fe content and decreased the $\mathrm{O}$ content (etch levels $200 \mathrm{~nm}, 500 \mathrm{~nm}$, and $600 \mathrm{~nm}$ ). This suggests that the amount of Fe oxide produced on the surface increased as the heat-treatment temperature increased.

In contrast, the amount of oxide was constant at etch level $350 \mathrm{~nm}$ until $950{ }^{\circ} \mathrm{C}$ and subsequently increased to $750 \mathrm{~nm}$ from $1000^{\circ} \mathrm{C}$. Thus, the production of $\mathrm{Fe}$ oxide was inhibited up to $950^{\circ} \mathrm{C}$, and the effect of $\mathrm{Si}$ and $\mathrm{Sn}$ was relatively halved at $1000{ }^{\circ} \mathrm{C}$. The $(\mathrm{c}, \mathrm{d})$ graph shows the change in the contents of $\mathrm{Cr}$ and $\mathrm{Ti}$ as the temperature increases. The contents of $\mathrm{Cr}$ and $\mathrm{Ti}$ on the surface decreased with the direction of the base metal, implying that the oxidation ratio of $\mathrm{Cr}$ and $\mathrm{Ti}$ on the surface increased with temperature.

The (e, f) graph shows the change in content based on the depth direction of $\mathrm{Si}$ and $\mathrm{Sn}$ [20]. For specimen \#B with a high Si content, the ratio of oxidized $\mathrm{Si}$ on the surface was high. Moreover, Sn exhibited behavior similar to Si. This suggests that $\mathrm{Si}$ and $\mathrm{Sn}$ reacted with $\mathrm{O}$ to form oxide layers on the surface of specimen $\# \mathrm{~B}$, reducing the production rate of Fe oxide. Thus, the addition of Si and Sn contributed to an improvement in the passive film stability of the stainless steel.

\subsection{Corrosion test}

Graphs and data were obtained from the potentiodynamic polarization test results of each specimen for the various heat-treatment conditions, as shown in Figure 5 and Table 3. The overall corrosion resistance data of specimen \#B, including $\mathrm{Si}$ and $\mathrm{Sn}$, were relatively superior to specimen \#A. For the corrosion potential $\left(\mathrm{E}_{\text {corr }}\right)$ indicating the corrosion resistance of the material, \#A and \#B were measured in the range of -580 to $-570 \mathrm{mV}$ and -540 to $-530 \mathrm{mV}$, respectively. The corrosion potential of \#B was approximately $40 \mathrm{mV}$ higher than that of \#A, implying an improved resistance to corrosion on the surfaces of the stainless steel, due to the effect of $\mathrm{Si}$ and $\mathrm{Sn}[2,21]$. In addition, the $\mathrm{E}_{\text {corr }}$ of both specimens decreased when the temperature increased. This is considered to be a slight decrease in corrosion resistance, attributed to an increase in the material grain size.

The Nyquist plot of the EIS analysis allows comparison of the corrosion resistances of the \#A and \#B specimens, as shown in Figure 6 and Table 4. The $\mathrm{R}_{\mathrm{s}}$ was measured at 4.0 ohms for all specimens. However, the $\mathrm{R}_{\mathrm{p}}$ for \#A and \#B were measured in the range 280-325 ohms and 505-510 ohms, respectively, indicating that $\# \mathrm{~B}$ has better corrosion resistance than \#A in the same corrosion environment [13,21]. Furthermore, the polarization resistance of specimen \#B showed a relatively smaller decrease with increasing temperature than specimen \#A, implying that specimen \#B has higher stability due to the temperature changes. Thus, the addition of $\mathrm{Si}$ and $\mathrm{Sn}$ contributed to the improvement in the corrosion resistance of the materials [6].

Table 3. Results of potentiodynamic polarization test by heat treatment conditions of \#A and \#B specimens

\begin{tabular}{|c|c|c|c|c|c|}
\hline & \multirow{2}{*}{ Condition } & \multicolumn{2}{|c|}{ Corrosion resistance } & \multicolumn{2}{|c|}{ Passive Range } \\
\hline & & $E_{\text {corr }}(\mathbf{m V})$ & $I_{\text {corr }}\left(\mu \mathrm{A} / \mathrm{cm}^{2}\right)$ & $I_{d}\left(\mu \mathrm{A} / \mathbf{c m}^{2}\right)$ & $\mathbf{E}_{\text {pit }}(\mathbf{m V})$ \\
\hline \multirow{3}{*}{$\# \mathbf{A}$} & $900^{\circ} \mathrm{C}$ & $-569 \pm 5$ & $160 \pm 20$ & $45.5 \pm 5$ & $391 \pm 5$ \\
\hline & $950^{\circ} \mathrm{C}$ & $-572 \pm 5$ & $280 \pm 20$ & $53.5 \pm 5$ & $388 \pm 5$ \\
\hline & $1000^{\circ} \mathrm{C}$ & $-577 \pm 5$ & $276 \pm 20$ & $48.3 \pm 5$ & $395 \pm 5$ \\
\hline \multirow{3}{*}{$\# \mathbf{B}$} & $900^{\circ} \mathrm{C}$ & $-535 \pm 5$ & $34 \pm 5$ & $15.8 \pm 10$ & $295 \pm 5$ \\
\hline & $950^{\circ} \mathrm{C}$ & $-520 \pm 5$ & $67 \pm 5$ & $10.7 \pm 10$ & $293 \pm 5$ \\
\hline & $1000^{\circ} \mathrm{C}$ & $-541 \pm 5$ & $82 \pm 5$ & $7.9 \pm 10$ & $290 \pm 5$ \\
\hline
\end{tabular}



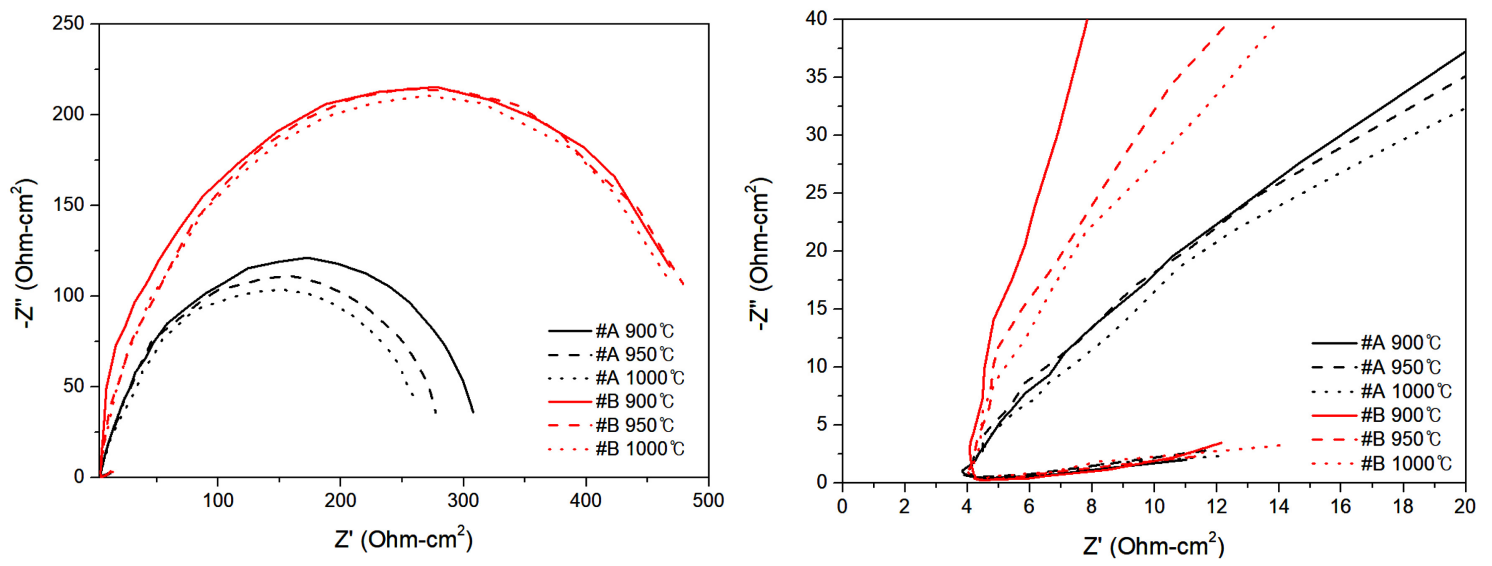

Fig. 6. Nyquist plot curves of EIS analysis results by heat treatment conditions for \#A and \#B specimens.

Table 4. Rs and Rp data of EIS analysis results by heat treatment conditions for \#A and \#B specimens.

\begin{tabular}{ccc}
\hline Condition & $\mathbf{R}_{\mathbf{s}}(\mathbf{O h m s})$ & $\mathbf{R}_{\mathbf{p}}(\mathbf{O h m s})$ \\
\hline \#A $900{ }^{\circ} \mathrm{C}$ & 4.0 & 325.9 \\
\#A $950{ }^{\circ} \mathrm{C}$ & 4.0 & 302.4 \\
\#A $1000^{\circ} \mathrm{C}$ & 4.0 & 287.4 \\
\#A $900{ }^{\circ} \mathrm{C}$ & 4.0 & 508.7 \\
\#A $9500^{\circ} \mathrm{C}$ & 4.0 & 507.5 \\
\#A $1000^{\circ} \mathrm{C}$ & 4.0 & 506.1 \\
\hline
\end{tabular}

The corrosion current density $\left(\mathrm{I}_{\text {corr }}\right)$ was less than $100 \mu \mathrm{A} /$ $\mathrm{cm}^{2}$ for specimen \#B compared to specimen \#A, indicating that the corrosion rate in the same environment was reduced. In addition, the $\mathrm{I}_{\text {corr }}$ increased with temperature. Furthermore, the increase in $I_{\text {corr }}$ with temperature was similar to the decrease in $\mathrm{E}_{\text {corr }}$. Thus, the decrease in corrosion resistance increased the corrosion rate [22].

The measured passive film maintenance current values $\left(\mathrm{I}_{\mathrm{d}}\right)$ of specimen \#B were between 7 and $20 \mu \mathrm{A} / \mathrm{cm}^{2}$, lower than that of specimen \# A $\left(45-53 \mu \mathrm{A} / \mathrm{cm}^{2}\right)$. This implies that the passive film of specimen \#B was produced in an electrochemically stable region, due to the improvement in passive film stability of the $\mathrm{SiO}_{2}$ and $\mathrm{SnO}_{2}$ layers.

The pitting potential $\left(\mathrm{E}_{\mathrm{pit}}\right)$ of specimen \#B was measured to be approximately $100 \mathrm{mV}$, lower than that of specimen \#A. This indicates that the destruction of passive film in \#B was faster, leading to the onset of pitting corrosion. Such behavior could have two causes. First, the Cr content of specimen \#B was approximately 2 wt.\% lower than that of \#A. However, the amount of added $\mathrm{Si}$ and $\mathrm{Sn}$ was only about 1 wt.\%.
Studies have reported that the value of $\mathrm{E}_{\mathrm{pit}}$ decreased by approximately $100 \mathrm{mV}$ each time the $\mathrm{Cr}$ content of the stainless steel decreased by 1 wt.\% [8,23]. However, the decrease in the $\mathrm{Cr}$ content of the stainless steel led to a decrease in the $\mathrm{Cr}_{2} \mathrm{O}_{3}$ content, which is the main component of the passive film. This reduces the Fe oxidation inhibiting effect on the surface; therefore, an appropriate content of $\mathrm{Cr}$ is essential for corrosion resistance [24,25].

A significant difference in $\mathrm{E}_{\text {pit }}$ of approximately $100 \mathrm{mV}$ was observed for specimens \#A and \#B. This suggests that the $\mathrm{Si}$ and $\mathrm{Sn}$ oxide layers added to \#B were equivalent to the corrosion resistance effect of approximately $1 \mathrm{wt} . \% \mathrm{Cr}$. Therefore, the corrosion resistance of specimen \#B might decrease because $\mathrm{Cr}$ was reduced less. The addition of $\mathrm{Si}$ and Sn could also supplement the corrosion resistance. Consequently, we were able to reduce the $\mathrm{Cr}$ content and confirm improvements in the corrosion resistance of the stainless steel by $\mathrm{Si}$ and $\mathrm{Sn}$. Second, Sn has a higher potential than Fe. Thus, the acceleration in pitting corrosion could be attributed to the galvanic effect based on the difference in electromotive force (EMF). Other studies have confirmed that when the passive film was destroyed and the pitting corrosion began, the galvanic effect between the Sn layers and the base metal accelerated the pitting corrosion of the base metal.

\section{Conclusions}

This study analyzed changes in the corrosion resistance of AISI 439 ferrite stainless steel with heat-treatment temperature and the amount of added $\mathrm{Cr}$, Si, and $\mathrm{Sn}$ contents, which 
changed the components of the surfaces and cross sections. The following conclusions were drawn from this study:

1. It was confirmed that adding $\mathrm{Si}$ and $\mathrm{Sn}$ to AISI 439 ferritic stainless steel increased its corrosion resistance.

2. As the heat-treatment temperature of stainless steel increased, the grain size increased slightly due to grain growth. This change is attributed to the reduced corrosion resistance of the materials. In addition, precipitates such as $\mathrm{Cr}$ carbide and $\mathrm{Ti}$ nitride were produced during the heat treatment, which commonly affect corrosion resistance.

3. As the heat-treatment temperature increased from 900 to $1000{ }^{\circ} \mathrm{C}$, the production of $\mathrm{Fe}$ oxide on the surface increased. This is the leading cause of reduced corrosion resistance. Simultaneously, the production of $\mathrm{Si}$ and $\mathrm{Sn}$ oxides on the surface increased. This inhibited production of the Fe oxide on the surface, thereby improving the passive film stability.

4. Although the suppression of $\mathrm{Fe}$ oxide up to $950{ }^{\circ} \mathrm{C}$ was confirmed, the oxide generation increased at temperatures above $1000{ }^{\circ} \mathrm{C}$. This suggests that the heat treatment temperature of $950{ }^{\circ} \mathrm{C}$ is most effective in the manufacturing process.

5. The $\mathrm{Si}$ and $\mathrm{Sn}$ added specimens showed improvement in corrosion potential and corrosion current density. It was also confirmed that a passive film was produced in electrochemically stable areas by reducing the passive maintenance current.

6 . The pitting potentials of the specimens containing $\mathrm{Si}$ and Sn were relatively low. This is believed to have affected the reduction in the passive film properties due to a $2 \mathrm{wt} \% \mathrm{Cr}$ reduction. Thus, further studies on the appropriate contents of $\mathrm{Cr}, \mathrm{Si}$, and $\mathrm{Sn}$ could simultaneously improve mechanical properties, formability, and corrosion resistance.

\section{Acknowledgements}

This work was supported by the Korea Institute for Advancement of Technology (KIAT) grant funded by the Korea Government (MOTIE) (P0002019, Human Resource Development Program for Industrial Innovation).

This work was supported by the National Research Foundation of Korea (NRF) [grant number 2020R1A5A 8018822], which is funded by the Korean government (MSIT)

\section{REFERENCES}

1. G. Cai, C. Li, D. Wang, and Y. Zhou, Materials Characterization 141, 169 (2018).

2. Z.H. Jiang, J.P. Han, Y. Li, and P. He, Ironmaking \& Steelmaking 42, 504 (2014).

3. X. Ma, J. Zhao, W. Du, X. Zhang, L. Jiang, and Z. Jiang, Materials Science and Engineering: A 685, 358 (2017).

4. J.S.d. Souza, L.A.d. Oliveira, I.J. Sayeg, and R.A. Antunes, Materials Research 20, 1669 (2017).

5. X.-J. Zhang, F. Gao, and Z.-Y. Liu, steel research international 88, (2017).

6. J.M. Kim, Y.K. Hyun, S.W. Song, G.D. Kim, Y.H. Son, and J.H. Sung, Journal of the Korean Society for Heat Treatment 27, 15 (2014).

7. C.A.D. Rodrigues, R.M. Bandeira, B.B. Duarte, G. Tremiliosi-Filho, V. Roche, and A.M. Jorge, Materials and Corrosion 70, 28 (2019).

8. Y. Yu, S. Shironita, K. Souma, and M. Umeda, Heliyon 4, e00958 (2018)

9. W. Ye, Y. Li, and F. Wang, Electrochimica Acta 51, 4426 (2006).

10. D.-Y. Lin, T.-C. Chang, and G.L. Liu, Scripta Materialia 49, 855 (2003).

11. Z. Dong, M. Li, Y. Behnamian, J.-L. Luo, W. Chen, B.S. Amirkhiz, P. Liu, X. Pang, J. Li, W. Zheng, D. Guzonas, and C. Xia, Corrosion Science 166, (2020).

12. N.D. Nam, M.J. Kim, Y.W. Jang, and J.G. Kim, Corrosion Science 52, 14 (2010).

13. H. Luo, H. Su, B. Li, and G. Ying, Applied Surface Science 439, 232 (2018).

14. H. Deng, D. Chen, Y. Wang, Y. Zhou, and P. Gao, Diamond and Related Materials 110, (2020).

15. Y. Li, J.-p. Han, Z.-h. Jiang, and P. He, International Journal of Minerals, Metallurgy, and Materials 22, 37 (2015).

16. R. Robin, F. Miserque, and V. Spagnol, Journal of Nuclear Materials 375, 65 (2008).

17. H. Luo, C. Dong, K. Xiao, and X. Li, RSC Advances 6, 9940 (2016).

18. T. He, Y. Bai, X. Liu, D. Guo, and Y. Liu, Metals and Materials International 24, 789 (2018).

19. X. Cheng, Z. Jiang, D. Wei, J. Zhao, B.J. Monaghan, R.J. Longbottom, and L. Jiang, Surface and Coatings Technology 258, 257 (2014). 
20. X. Cheng, Z. Jiang, D. Wei, L. Hao, J. Zhao, and L. Jiang, Tribology International 84, 61 (2015).

21. A. Bautista, A. González-Centeno, G. Blanco, and S. Guzmán, Materials Characterization 59, 32 (2008).

22. H.-b. Li, Z.-h. Jiang, H. Feng, H.-c. Zhu, B.-h. Sun, and Z. Li, International Journal of Minerals, Metallurgy, and Materials 20, 850 (2013).
23. J.K. Kim, Y.H. Kim, J.S. Lee, and K.Y. Kim, Corrosion Science 52, 1847 (2010).

24. B. H. Choe, S. W. Lee, J. K. Ahn, and J. Lee, Korean J. Met. Mater. 58, 583 (2020).

25. B. H. Choe, S. W. Lee, J. K. Ahn, J. Lee, and T. W. Lim, Korean J. Met. Mater. 58, 653 (2020). 